\title{
Sciendo
}

LATVIAN JOURNAL OF PHYSICS

AND TECHNICAL SCIENCES

2019, N 1

DOI: $10.2478 /$ lpts-2019-0003

\section{STUDY OF THE PROCESSES OF NEAR IDENTICAL, NANOPRENE, NEURO PROGENITOR ELECTRIC DRIVE}

\author{
Viktor M. Buyankin \\ Bauman Moscow State Technical University, 2-nd Baumanskaya Str. 5, 105005 , \\ Moscow, RUSSIA \\ Viktor-Buyankin@yandex.ru
}

\begin{abstract}
The article deals with the artificial multilayer neural network with direct signal transmission and reverse error propagation, which operates in the mode of identification of static and dynamic characteristics of the electric drive. To study processes of nearly identical, nanoprene of neuroprogenitor has been developed by the research stand, which is described in the article. As a result of research on the stand, the results show that the neural network is well enough to identify the static and dynamic characteristics of the electric drive.
\end{abstract}

Keywords: clustering, drive, materials science, neural network, training

\section{INTRODUCTION}

Neural networks are used in industrial units in the presence of disturbing effects on the control object when traditional solutions in control systems are not effective enough [1]-[4]. Management of electric drive complexes, using neural networks, is advisable when changing in a wide range of parameters of the mechanical part and modes of operation of the electric drive when the speed or accuracy of traditional control systems with linear regulators is insufficient [5].

The neural network is able to perform a variety of functions: managing dynamic objects, hardware diagnostics, forecasting, production management, monitoring of technological processes [6]. When using neural networks, it is possible to carry out parallel processing of information by all links, which significantly accelerates the processing of information [7]. Neural networks are characterised by the ability to learn and summarise accumulated knowledge [8]- [11]. The network trained on a limited set of data is capable of further generalising the received information and processing the data which were not used at its training [12].

Multilayer neural network performs the function of an adaptive object controller in the dynamic control system. In this case, the neural network in the learning process simultaneously forms the optimal control effect on the input of the system actuator in the sense of minimality of the required target function [13]. The goal of learning the network and the goal of managing the object are the same, 
which means setting a common target function [14]. There is a possibility when the network operation consists of two stages: the stage of training the network optimal control law, calculated in advance on the basis of any theory in accordance with the specified training functionality; and the stage of reproduction of the optimal control function at the outlet of the network or at the entrance of the actuator. Here the target functions of network learning and object management can differ from each other. The latest version of the multi-layer neural network for management has been found to be predominant for a number of reasons [15].

\section{METHODS}

A multilayer neural network is used as the state IDs of the nonlinear dynamic objects, successfully competing with traditional linear and nonlinear identities. It should also be noted that a multilayer neural network is used as an optimizer for tuning traditional adaptive regulators [16]. The network is fully defined if its architecture, i.e., the method of connection of basic elements is specified, and the algorithm of its training is adopted in accordance with the method of training [17]. Neural networks allow creating a model of the object that accurately conveys its dynamics, while not requiring additional knowledge about the structure and parameters of the object [18]. Only the input and output signal values are the necessary data, so the object is represented as a black box.

Neural networks are used in industrial units in the presence of disturbing effects on the control object when traditional solutions in control systems are not effective enough. Management of electric drive complexes, using neural networks is advisable when changing in a wide range of parameters of the mechanical part and modes of operation of the electric drive when the speed or accuracy of traditional control systems with linear regulators is insufficient.

\section{RESULTS AND DISCUSSION}

The most common architectures of neural networks are direct distribution networks, recurrent neural networks, self-organizing maps or Kohonen network, convolutional neural networks, and radial basis functions. The number of neural network architectures is tens, and for different types of tasks, different types of neural networks are most effective. Neural networks allow creating a model of the object that accurately conveys its dynamics, while not requiring additional knowledge about the structure and parameters of the object. Only the input and output signal values are the necessary data, so the object is represented as a black box. Let us consider management with predictive models [5], [19], [20]. The controller uses a neural network model of a nonlinear object to predict the behaviour of the control object on different types of input actions. Building an object model is called system identification. The process of constructing a neural network model of an object consists of the following steps: 1) data collection and normalization for training; 2) choice of network architecture and learning algorithm; 3) training; 4) checking the adequacy of training. 
The constructed object model is used to create a control system for this object. The task of the neurocontroller is to calculate the control signal that will optimise the operation of the object for a certain period of time. A prediction error between the output of a control object and the output of its neural network model is used as a signal to train the network.

Neural networks and neuro-controllers can be used to control various objects, including electric drives of various mechanisms, while the neuro-controller produces a control signal. The neural network on the first iterations of the learning process can give control signal values that are not valid, for example, for an electric drive. Therefore, the configuration of the neurocontroller should be done using the object model.

To study processes of near identical, nanoprene of neuroprogenitor was developed by the research stand sketch, which is shown in Fig. 1. The basis of the stand design is standard laboratory table 1. A panel with sockets is mounted vertically on the table to measure the required parameters of various units of the electric drive control system. This panel is assigned a blank panel with 2 done on it mnemonic in the block diagram of the actuator, which is shown in Fig. 1, where inappropriate places, the indication of the rotation angle and speed of the drive shaft by means of LEDs and seven-segment elements are displayed. DC motor (3), load device (4) and a pulse sensor (5) are mounted on special vertical (to save space) frame - a rack mounted on the floor to the right of the bench of the Microcomputer unit of the programming device (7) and the power source load device (8) located on the lid of the instrument tables (9), which is mounted to the left of the stand with the engine. In the Cabinet (9), crate (10) is mounted with the electronic components of the control system. In the crate, there is also the necessary functional switching equipment. Such arrangement and constructive execution of block (10) give the chance of free access to printed circuit boards of electronic blocks in case of their study or repair. The proposed location of the equipment, a corresponding functional block diagram (Fig. 1) of electric drive systems, ensures efficient and safe operation with the bench.

Figure 1 presents a drive with a PBST-22 DC motor, which has the following nominal parameters: $\mathrm{P}=0.6 \mathrm{~kW}, \mathrm{U}=110 \mathrm{~V}, \mathrm{I}=7 \mathrm{~A}, \mathrm{n}=1000 \mathrm{vol}$. The circuits of negative feedback are closed through a microcomputer using a pulse sensor, from which you can get information about the speed and angle of rotation of the motor shaft. The functional scheme of the electric drive consists of micro-computers, programmer, interface, code-phase converter, pulse distributor, power unit, DC motor, Tacho, pulse sensor unit angle code with digital indication of the angle of rotation and the speed of the motor shaft. To study and measure the mechanical characteristics of the stand, a load device is provided. The enlarged algorithm of operation of the electric drive can be represented as follows: electric drive with DC motor is made on the principle of a non-autonomous digital automated control system, in which a comparison of the master and the workable codes takes place directly in the micro-computer.

The control signal from the micro-computer is given to the converter code phase and then through the power unit is fed to the executive DC motor. Misalignment error between the driver and the feedback is worked out in the digital correcting device of the microcomputer. Micro-computer has a modular principle of 
construction, i.e., all functional blocks are made in the form of structurally complete devices (modules), communication between which is carried out through a single channel of information exchange. Thus, a microcomputer is a system of modules united by a channel. Parallel exchange links connect the CPU, memory, and all external devices. All modules are connected to the channels of the micro-computer. Communication through the channels is closed, i.e., the control signal supplied by the active device must receive a signal from the passive device.

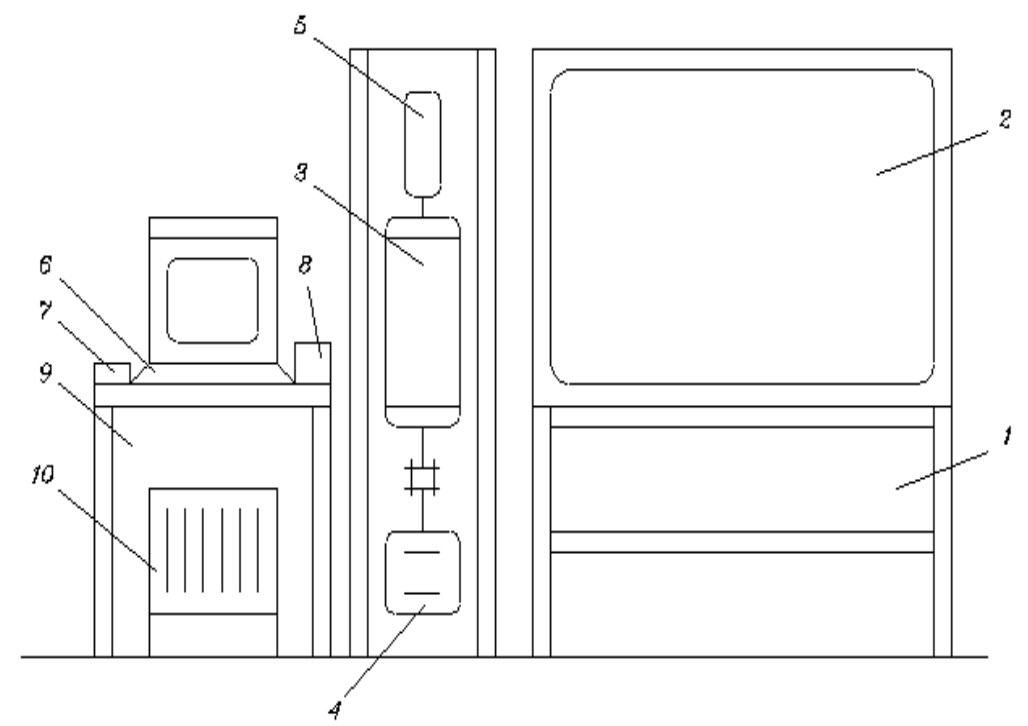

Fig. 1. Stand of the drive for research of near identical, nanoprene, neuroprogenitor: 1 - programmer, 2 - traffic, 3 - controller, 4 programs of name identifier, nanoprene, propagation, 5 - timer, 6 - UI, 7 - power unit, 8 - transducer angle code, 9 - in a network: 10 - current sensor, 11 - motor, 12 - speed sensor 13 - sensor of the rotation angle.

The main element of the microcomputer is the central processor, which controls the distribution of the time of use of the channel by external devices and performs all the necessary arithmetic and logical operations for processing information. It contains 16 general-purpose high-speed registers, which are widely used in various operations. At the same time, the CPU performs several operations, the team extended arithmetic can be treated as sixteen-bit or 8-bit words.

The ability to use eight addressing methods allows for highly efficient processing of data stored in any memory cell or register. The operating unit performs the operations of generating addresses of commands and operands, logical and arithmetic, storing operands and results. The firmware control unit produces a sequence of micro-commands based on the received command code. It encodes a complete set of micro-commands for all types of commands. The interrupt block organises a priority interrupt system, performs reception and pre-processing of internal and external interrupt requests of the computational process.

The interface unit performs the exchange of information among devices located on the system highway, performs arbitration during operations, direct 
memory access. A sequence of control signals of the system trunk is formed in the interface block. The block system of highways connects the inner pipe with the outer. It manages amplifiers receiving and issuing information on the combined conclusions of addresses and data.

The functional scheme of the electric drive, which represents the three-circuit digital tracking system of automatic regulation, is presented in Fig. 2. The contours of the negative OS are closed with the help of current sensors, speed, and angle of the shaft of the motor through a microcomputer.

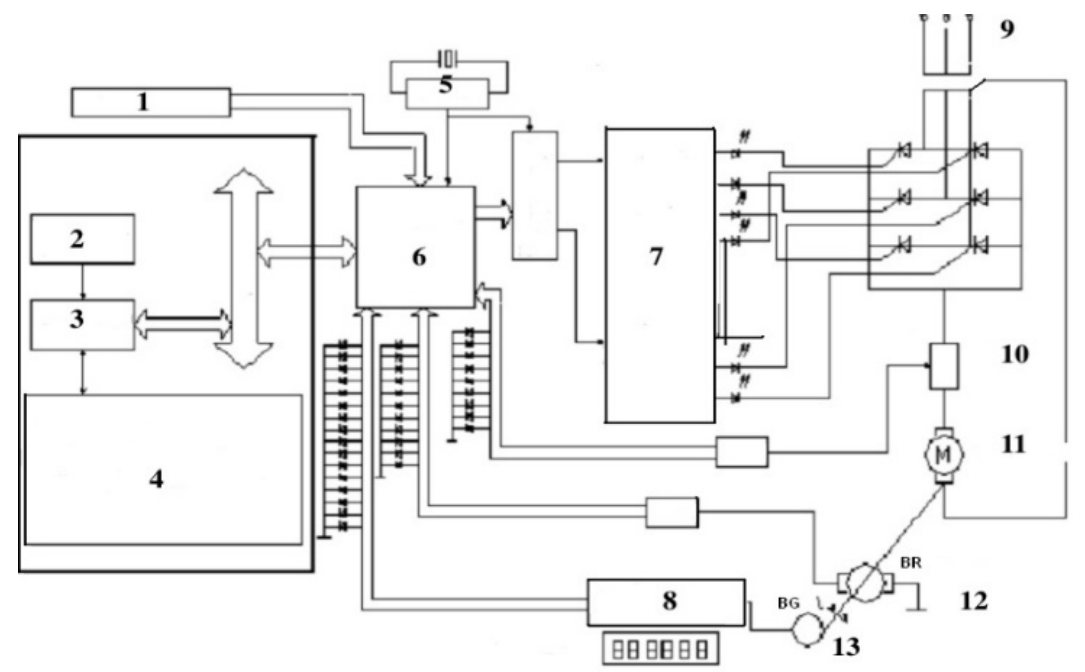

Fig. 2. A functional diagram of the electric drive: 1 - programmer, 2 - traffic, 3 - controller, 4 programs of name identifier, nanoprene, propagation, 5 - timer, 6 - UI, 7 - power unit, 8 - transducer angle code, 9 - in network: 10 - current sensor, 11 - motor, 12 - speed sensor, 13 - sensor of the rotation angle.

The actuator consists of a macro-computer, interface, converter "code-phase" of distributor pulses, a block of the thyristor, DC motor, Tacho-generator, current sensors, speed and angle of the shaft of the motor, the two ADC converter "anglecode", timer, programmer and load of the device. The microcomputer performs the function of processing the signals from the sensors to the OS that carries out the preset movement program. Adaptive reconfigurable controller, which is implemented in software, provides optimum operation. The channel of communication with external devices in microcomputers is a common bus. The interface provides communication with external devices, microcomputers, delirium addresses of the sensors OS and generates return service signals. The decoded signals of the respective bits are used as address signals of the blocks of the drive. The interface has two channels for transmission from the microcomputer to the external device and receiving data from external devices. Command INPUT or OUTPUT to the bus channel of the microcomputer connects certain external devices.

The angle-code converter measures the rotation angle of the motor shaft in a parallel binary code with fifteen digits. Upon request, personalized information is sent to a receiver channel interface. Converter "code-phase" converts the parallel 
binary code at the output of the microcomputer in the control pulses, a phase shift which is directly proportional to the binary code. Distributors of pulses in sequence provide the control electrodes of the thyristor VDI...VD6 control pulses. The timer, which is based on a quartz oscillator, provides a highly stable frequency of time signals for synchronizing the operation of all nodes of the functional circuit of the electric drive. ADC is used to convert analogue signals from the current sensor and Tacho-generator in a parallel binary code and transmit these signals to microcomputer.

The thyristor unit consists of thyristors and a three-phase transformer, whose secondary windings are connected to a three-phase star with a zero output. The transformer matches the mains voltage with the motor supply voltage and limits short-circuit currents. The motor is connected at one end to the zero output of the secondary windings of the transformer, and the other - to the inverter and rectifier groups of thyristors. The current sensor is a measuring device of the resistive type.

Tacho is an element of automatic control systems, the input parameter for which is the rotational speed (angular position) of the Tacho shaft, and the output the voltage directly proportional to the input value. Pulse type feedback sensor includes three main parts: mechanical, optical and electronic. These signals have a rectangular shape, their amplitudes are shifted relative to each other by $90^{\circ}$. Pulse repetition rate is proportional to the measured rotational speed, and the number of pulses - the angle of rotation of the motor shaft.

To display information about the rotation angle and speed of the motor shaft, a digital display is provided on the stand. The rotation angle is displayed using the seven-segment indicator made on the LEDs, which receives signals from the decoder that translates the binary code into the control code of the seven-segment indicators. The load device, consisting of an autotransformer T2, voltmeter PV, ammeter RA and powder coupling, is used to create the load moment on the motor shaft, which is directly proportional to the current flowing in the powder coupling circuit.

The laboratory setup consists of a microcomputer, which is administered by the keyboard of the programming device and the power unit mounted on the supporting metal structures. Electronic function blocks are located in a special device (under the computer). Beside the computer there is a stand, which shows a functional diagram of the actuator for the study of processes of near identical, nanoprene, neuroprogenitor physical processes in DC motors.

The motor speed at low frequencies is unstable and the coefficient of unevenness increases with a decrease in the speed. This is understandable, since with the decrease in the motor speed, the nonlinearity of the type of dry and viscous friction in the bearings of the motor, the nonlinearity of the type of magnetic saturation in the stator and rotor cores, additional losses due to the dispersion of the electromagnetic field created by the excitation winding begin to affect more and more.

To identify static and dynamic characteristics, it is necessary to use a neural network containing 20 neurons with tansig activation function in the first input layer and 1 neuron in the output with purelin activation function, which is described by the system of equations: 


$$
Y_{1}=Y_{0} Z^{-1} \cdot Y_{2}=Y_{0} Z^{-2} \cdot Y_{3}=Y_{0} Z^{-3}
$$

The output signals of the neural network were detained in 1, 2, 3 tact. Equations of the 1st output layers of neurons:

$$
\begin{aligned}
& E_{1}=X_{0} W_{1}+Y_{0} W_{\mathrm{L}}+Y_{1} W_{\mathrm{B}}+Y_{2} W_{4}+Y_{3} W_{5}+B_{1} \\
& E_{2}=X_{0} W_{2}+Y_{0} W_{2}+Y_{1} W_{3}+Y_{2} W_{\text {g }}+Y_{3} W_{\text {ฐ }}+B_{2} \\
& E_{2}=X_{0} W_{211}+Y_{0} W_{212}+Y_{1} W_{213}+Y_{2} W_{214}+Y_{3} W_{215}+B_{1}
\end{aligned}
$$

Equations of the 2nd output layer of neurons:

$$
\left.\begin{array}{l}
R_{1}=\tan \operatorname{sig}\left(E_{1}\right) \\
\ldots \ldots \ldots \ldots \ldots \ldots \ldots \ldots \ldots \ldots \ldots \ldots \ldots \ldots \ldots \\
R_{2}=\tan \operatorname{sig}\left(E_{2}\right) \\
Y_{0}^{\prime}=R_{1} W_{1}^{\prime}+\ldots \ldots \ldots \ldots . .+R_{2} W_{2}^{\prime}+B_{1}^{\prime} \\
Y_{0}=\text { pureline } Y_{0}^{\prime}
\end{array}\right\}
$$

Figures 3-4 demonstrate structural diagrams of the neural network.

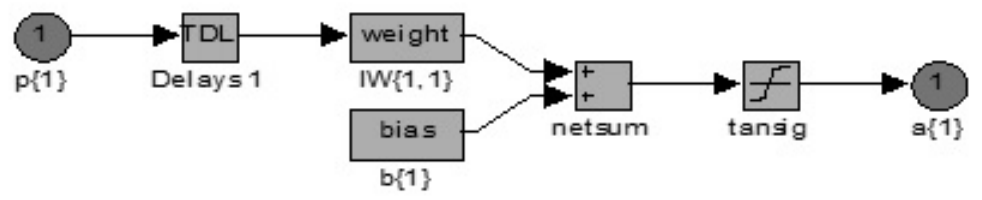

(a)

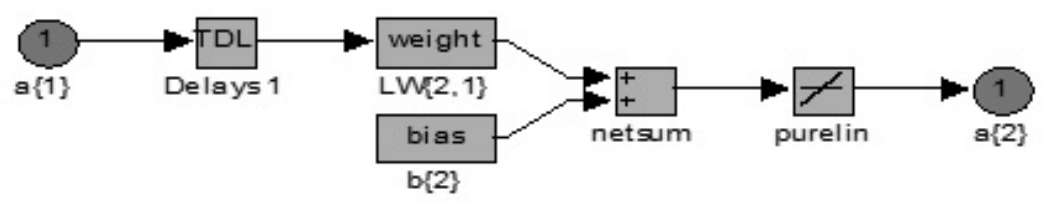

(b)

Fig. 3. The structural diagram of neural network: (a) first layer, (b) second layer. 


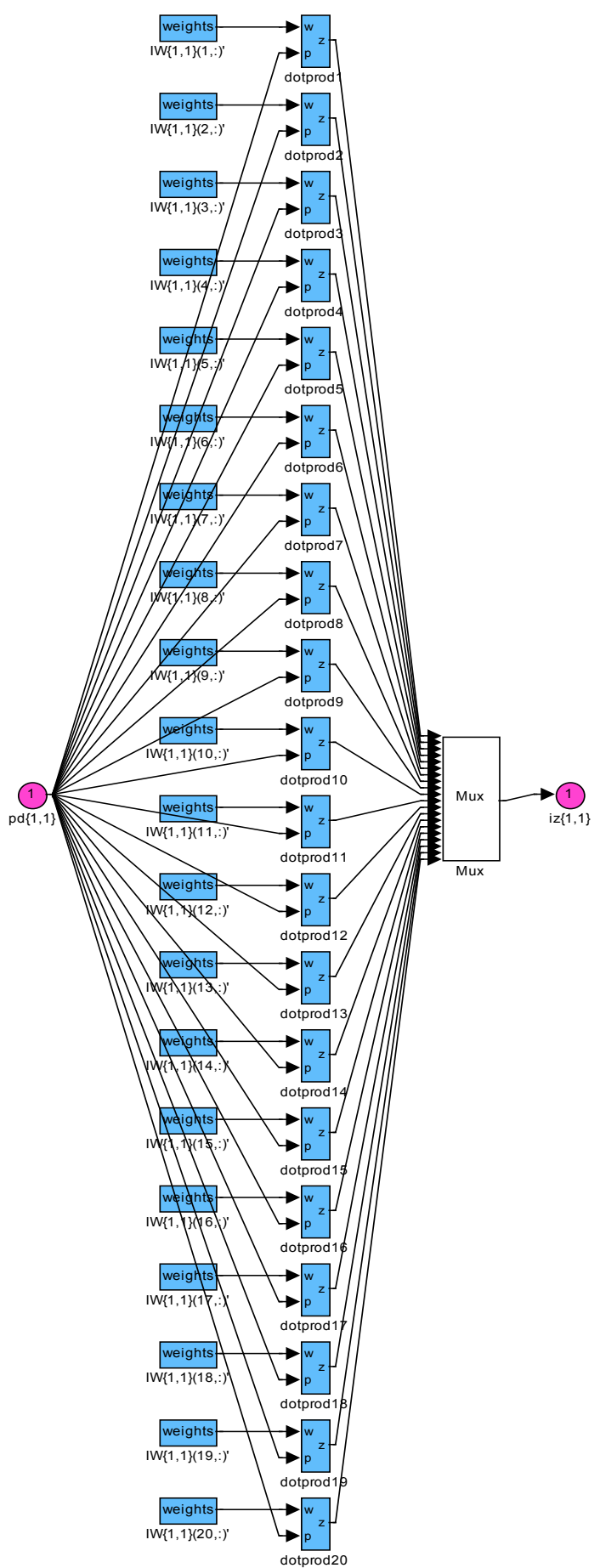

Fig.4. A detailed diagram of the neural network.

The results of near identical static and dynamic characteristics of the actuator are shown in Figs. 5, 6, 7. 


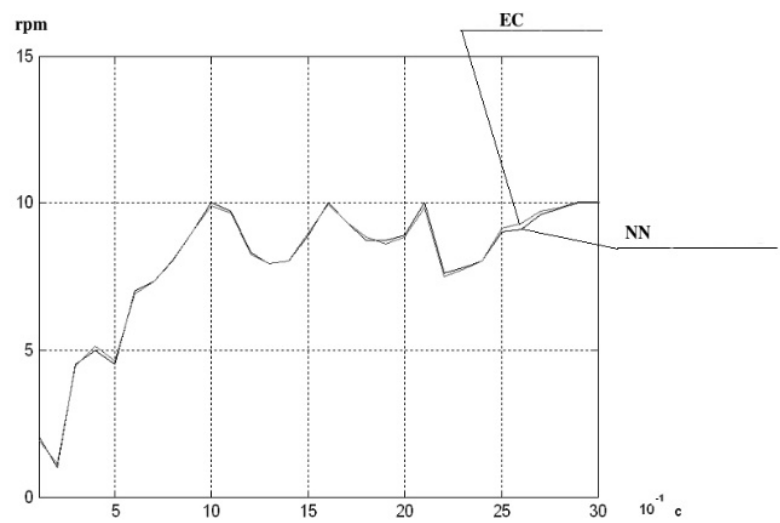

Fig. 5. Near identical operation at a preset speed $9 \mathrm{rpm}$ : ED - electric drive, $\mathrm{NN}$ - neural network.

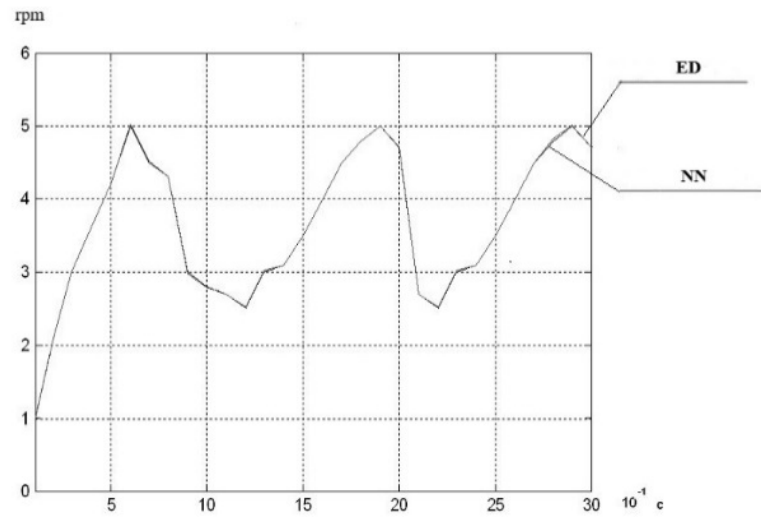

Fig. 6. Near identical operation at a preset speed $4 \mathrm{rpm}$ : $\mathrm{ED}$ - electric drive, $\mathrm{NN}$ - neural network.

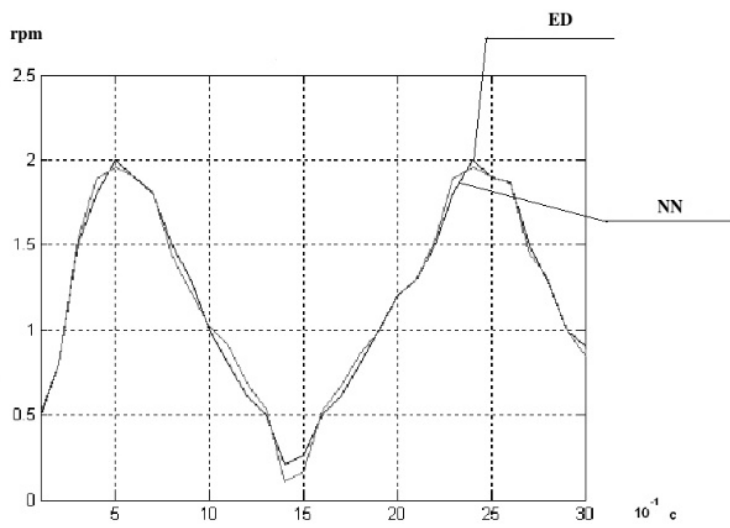

Fig. 7. Near identical operation at a preset speed of $1 \mathrm{rpm}$ : $\mathrm{ED}$ - electric drive, $\mathrm{NN}$ - neural network.

Thus, as a result of experimental studies on the stand, the results were obtained, which showed that the neural network could accurately identify the static and dynamic characteristics of the electric drive. 


\section{CONCLUSIONS}

From the presented graphs, it can be seen that the neural network copes with the task of identification, with high accuracy repeating the dynamics of the model of the electric drive in the entire range of its operation. This method can be applied to electric drives of any complexity. The disadvantage of the method is the need for learning the model to test its adequacy with new data that did not participate in the training. This is due to the danger of re-training the network. This problem can be solved by programmatically controlling the learning outcome before application. Thus, the use of neural networks as an alternative to existing algorithms for identification and construction of linear multidimensional mathematical systems is quite possible.

An expert system of forecasting the technical condition of the product on the basis of the mathematical apparatus of artificial neural networks (ins) has been proposed. Hybrid artificial neural networks are a combination of different kinds of neural networks and concepts of their training. They are designed to solve various kinds of problems, such as pattern recognition, prediction, approximation of functions, etc.

The problem of forecasting the technical condition of the product on the basis of the mathematical apparatus of artificial neural networks is formalized through the problem of pattern recognition. The data on the predicted variable for a certain period of time form an image, the class of which is determined by the value of the predicted variable at some point outside of this interval, i.e., the value of the variable through the prediction interval.

\section{REFERENCES}

1. Fard Masoumi, H.R., Basri, M., Kassim, A., Kuang Abdullah, D., Abdollahi, Y., \& Abd Gani, S.S. (2014). Comparison of estimation capabilities of the artificial neural network with the wavelet neural network in lipase-catalyzed synthesis of triethanolamine-based esterquats cationic surfactant. J Surfactants Deterg., 17(2), 287-294. doi: 10.1007/ s11743-013-1539-0.

2. Mao, W., Wang, W., Dou, Z., \& Li, Y. (2018). Correction to: Fire recognition based on multi-channel convolutional neural network. Fire Technol. doi: 10.1007/s10694-0180705-3.

3. Ayhan, T., Karlik, B., \& Tandiroglu, A. (2008). Flow geometry optimization of channels with baffles using neural network and second law of thermodynamics. Comput Mech., 42(3), 481. doi: 10.1007/s00466-006-0083-4.

4. Yamada, T. (2009). Remarks on the tracking method of neural network weight change for a learning-type neural network feed-forward feed-back controller. Artif Life Robot., 14(3), 384. doi:10.1007/s10015-009-0690-1.

5. Buyankin, V.M., Vasiliev, V.V., Tikhomirov, E.L., \& Tochilina, N.S. (1983). Drive control in microprocessor systems. In Microprocessor Technology in CNC Machine Tools: Sat. Scientific Papers (pp. 43-51). Moscow: ENIMS.

6. Posyagin, A.I., \& Yuzhakov, A.A. (2013). Development of a two-layer neural network for a self-routing analog-to-digital converter based on a neural network. Russ Electr Eng., 84(11), 602-605. doi: 10.3103/S1068371213110114. 
7. Lin, H-L., Chou, T., \& Chou, C-P. (2007). Optimization of resistance spot welding process using taguchi method and a neural network. Exp Tech., 31(5), 30-36. doi:10.1111/j.17471567.2007.00186.x.

8. Virili, F., \& Freisleben, B. (2001). Neural network model selection for financial time series prediction. Comput Stat., 16(3), 451-463. doi: 10.1007/s001800100078.

9. Liu, P., Shi, R., \& Gao, W. (2018). Erratum to: Estimating leaf chlorophyll contents by combining multiple spectral indices with an artificial neural network. Earth $\mathrm{Sci}$ Informatics, 11(1), 157. doi: 10.1007/s12145-017-0325-3.

10. Alkhasawneh, M.S., \& Tay, L.T. (2017). A hybrid intelligent system integrating the cascade forward neural network with elman neural network. Arab J Sci Eng. doi: 10.1007/s13369-017-2833-3.

11. Wang, H., Lv, Y., Chen, H., Li, Y., Zhang, Y., \& Lu, Z. (2018). Erratum to: Smart pathological brain detection system by predator-prey particle swarm optimization and single-hidden layer neural-network. Multimed Tools Appl., 77(3), 3887, doi: 10.1007/ s11042-017-4391-9.

12. Patra, J.C., Ang, E.L., Chaudhari, N.S., \& Das, A. (2005). Neural-network-based smart sensor framework operating in a harsh environment. EURASIP J Adv Signal Process, 2005(4), 498294. doi:10.1155/ASP.2005.558.

13. Shaltaf, S. (2004). Neural-network-based time-delay estimation. EURASIP J Adv Signal Process, 2004(3), 654087. doi: 10.1155/S1110865704309261.

14. Nemmour, H., \& Chibani, Y. (2005). Neural network combination by fuzzy integral for robust change detection in remotely sensed imagery. EURASIP J Adv Signal Process, 2005(14), 413784, doi:10.1155/ASP.2005.2187.

15. Dmitriev, A.S., Emelyanov, R.Y., Lazarev, V.A., \& Chibisov, V.V. (2017). Simulation of dynamics of the neural ensemble in an active wireless network. $J$ Commun Technol Electron, 62(10), 1148-1151. doi: 10.1134/S1064226917100035.

16. Hartmann, C., Lazar, A., \& Triesch, J. (2015). Key features of neural variability emerge from self-organized sequence learning in a deterministic neural network. BMC Neurosci., 16(1), 266. doi: 10.1186/1471-2202-16-S1-P266.

17. Nugent, C.D., Lopez, J.A., Smith, A.E., \& Black, N.D. (2002). Prediction models in the design of neural network based ECG classifiers: A neural network and genetic programming approach. BMC Med Inform Decis Mak., 2(1), 1. doi: 10.1186/1472-69472-1.

18. Rohit, S., \& Chakravarthy, S. (2011). A convolutional neural network model of the neural responses of inferotemporal cortex to complex visual objects. BMC Neurosci., 12(1), 35. doi: 10.1186/1471-2202-12-S1-P35.

19. Grasel, F.D.S., \& Fontoura, L.A.M. (2016). Computacional study of the electronic effects in rotational barrier of the N-arilcarbamatos N-CO bond. Periodico Tche Quimica, 13(25), 7-15.

20. Buyankin, V.M., \& Vasiliev, V.V. (1982). Digital servo drive with separate control reversing thyristor Converter. In Electric and Hydraulic Drive of CNC Machines and Industrial Robots: Sat. Scientific Papers (pp. 78-86). Moscow: ENIMS. 


\title{
GANDRĪZ IDENTISKAS, NANOPRĒNA, NEIRO-PROGENERATORA ELEKTRISKĀS PIEDZIN̦AS PROCESA PĒTĪJUMS
}

\author{
V. M. Bujankins
}

Kopsavi $1 \mathrm{kums}$

Rakstā aplūkots mākslīgs daudzslāņu neironu tîkls ar tiešu signālu pārraidi un kḷūdu atgriezenisko izplatǐšanu, kas darbojas elektriskās piedziņas statisko un dinamisko īpašību identifikācijas režīmā. Lai izpētītu gandrīz identiskus procesus, pētījuma stendā, kas aprakstīts rakstā, ir izstrādāts neiro-progeneratora nanoprēns. Pētījuma rezultāti liecina, ka neironu tīkls ir pietiekami labs, lai noteiktu elektriskās piedziņas statiskās un dinamiskās īpašības.

22.12.2018. 